\title{
A Study on Role of Clinical Pharmacist in Identification and Prevention of Medication Errors at a Teritiary Care Hospital
}

\author{
Manjunath Gandage*, Sheetal Ninne, Pooja salimath, Prathusha Reddy, Shweta Buchanalli, Harshitha \\ Reddy, Kishwanth Samson
}

Department of Pharmacy Practice, HKES's MTRIPS, Kalaburagi-585 105, Karnataka, INDIA.

\begin{abstract}
Introduction: Medication errors are at forefront and common provision of modern healthcare and one of the many hazards of hospitalization. The problem is of multidisciplinary and multifactorial in nature. Objective: Identification and prevention of medication errors. Methods: A prospective observational study was conducted over a period of 6 months in a tertiary care hospital. Patients were selected randomly by considering the study criteria. Medication errors were analyzed by using Treatment chart review. The severity levels of medication errors have been analyzed by using the National Coordinating Council for Medication Error Reporting and Prevention (NCCMERP) proposed index for categorizing medication errors. Results: A total of 681 cases were selected randomly, in which 199 (29.22\%) patients showed, 221 medication errors. Out of which 128 (57.91\%) errors were actual errors and 93 (42.08\%) errors were categorized as potential errors. Prescribing errors were $82.80 \%$, followed by Administration errors $23(10.40 \%)$, Dispensing errors $08(3.61 \%)$ and $07(3.16 \%)$ were Monitoring errors. Anti-infective drugs were the most common class of drugs in which errors occurred 45 (21.02\%). Most of the errors in our study resulted in No Error $42.53 \%$ (category A), $44.34 \%$ (category B, C and D) resulted in Error No Harm, $13.12 \%$ (category $E, F, G, H$ ) resulted in Error Harm. No incidence of Error Death was reported. Conclusion: The incidence of medication errors was significantly high and it is essential to establish medication error reporting system. Study results shows that there were more number of potential errors which can be preventable. Clinical pharmacist can play a vital role in Identification and prevention of medication errors
\end{abstract}

Key words: Medication errors, Clinical Pharmacist, Antibiotics.

\section{INTRODUCTION}

The healthcare system is extremely complex. It involves critical situations of risk, an interaction between multiple professionals and institutions and depends on significant support from technology. The characteristics of the system may heighten the risk of mistakes and worsen the consequences of these mistakes. In this sense, it is important to assess risk and damage to patients in the search for ultimate patient safety. The World Health Organization definition of patient safety establishes that unnecessary harm or potential harm associated with healthcare should be reduced to an acceptable minimum. ${ }^{1}$
Rational pharmacotherapy involves the appropriate use of medications for the patients to their clinical needs, in doses that meet their own individual requirements, for an adequate period of time and at the lowest cost to them and their community. ${ }^{2}$

\section{Error}

'A failure to complete a planned action as intended, or the use of an incorrect plan of action to achieve a given aim. $^{3}$
DOI: 10.5530/ijopp.11.4.41

Address for correspondence: Manjunath G Gandage, Asst Prof, Department of Pharmacy Practice, HKES's College of Pharmacy (MTRIPS), Sedam road, Gulbarga- 585 104, Karnataka, INDIA. Phone no: 9632326585 Email Id: mggandage@gmail. com

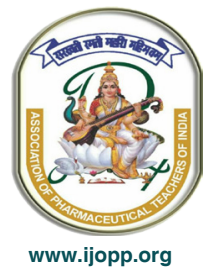




\section{Medication Errors}

Medication errors may be defined as "Any preventable event that may cause or lead to inappropriate medication use or patient harm while the medication is in the control of the healthcare professional, patient, or consumer". Such events may be related to professional practice, health care products, procedures and systems including: prescribing; order communication; product labelling, packaging and nomenclature; compounding; dispensing; distribution; administration; education monitoring; and use. The error may be related to professional practice, to healthcare products, to procedures, to communication problems (including prescribing, product labeling, packaging and nomenclature), to compounding, to dispensing, to distribution, to administration, to education, to monitoring and to the proper use of medications. ${ }^{4}$

Medical errors are events that are considered as a threat to patient well-being that should not happen or recur. ${ }^{5}$

Incidence rates of adverse drug events amongst adults admitted to the hospital have ranged from 2 to 7 per 100 admissions. Approximately, 28\% of adverse drug events (ADEs) are related to medication errors and are, therefore, judged to be preventable. This issue has also received considerable attention in the lay press. ${ }^{6}$

\section{Role Of Pharmacist In Reducing Medication Errors}

Like other health care professionals, pharmacists also possess valuable expertise and training. With their background in assessing and resolving medication use system deficiencies, they are in a unique position of being appropriate initiators of a collaborative interdisciplinary dialogue. With the evolution and popularization of the concept of pharmacy practice, the windows are open for pharmacists in India, to apply their knowledge and expertise in the quest to make health care safer for the patient and the public. The pharmacists have to move to the forefront and offer their expertise the administrators. Whenever medication accidents and tragedies occur, no one generally thinks, in India, to find out what the pharmacists have to say. The contemparorary practicing pharmacists have to assume new roles and responsibilities in patient care. They have to assume responsibilities for leading indisciplinary problems problem solving group to avoid reinventing the wheel. The pharmacists can get the pharmacy literature on mediction error from the website of ASHP which houses a center on patient safety. They can also build a relationship of respect and exchange ideas with champions for safety in order disciplines. Practicing pharmacists have to make contacts with pharmacists in other practice settings that have error reduction system.
Experts from other practice settings that have errors reduction system. Experts from other high-risk industries like aviation, nuclear power and chemical manufacturing may be invited to speak to pharmacists about how they have developed a system that anticipates and accounts for error. The pharmacists have to assume leadership roles as researchers in patient safety. Research in patient safety combines all the traditional qualitative sciences well known to health care professionals with other health care related areas of safety; like sociology, psychology, engineering, law and others. By virtue of their size and stature, associations can often accomplish objectives that individual's cannot. ${ }^{7}$

\section{METHODOLOGY}

A prospective observational study was conducted over a period of 6 months in a tertiary care hospital. Patients admitted to the department of medicine and paediatric were selected randomly and followed from date of admission to date of discharge enrolled into the study by considering the study criteria. Patient Informed consent will be taken from each patient at the time of enrollment into the study. Details regarding patient demography and medication will be collected from the case sheets and patient counseling will be noted in a suitably designed patient data collection proforma. The data collected will be analyzed for Identifying Medication errors such as Prescribing Errors, Dispensing Errors and Administration Errors. Each reported medication error was assessed using the National Coordinating Council for Medication Error Reporting and Prevention (NCCMERP) proposed index for categorizing medication errors.

\section{RESULTS}

Total No. of prescriptions collected

Total No. of prescriptions with errors

Total No. of errors in 199 prescriptions

Percentage

$29.22 \%$

Table 1: Details on Gender Distribution among the Patient in the Study.

\begin{tabular}{cccc} 
SI. No. & Description & Total & Percentage \\
\hline 1. & Male & 122 & $61.30 \%$ \\
2. & Female & 77 & $38.70 \%$ \\
\hline
\end{tabular}




\section{RESULTS AND DISCUSSION}

A total of 681 prescription of patients admitted to the department of general medicine and paediatric were selected randomly and analyzed. Medication Errors were identified day to day by treatment chart review. Out of 681 cases, 199 (29.22\%) are having medication errors of 221 errors which is similar to the study conducted by Sanjay $\mathrm{G}$ et al. ${ }^{8}(25.7 \%) 27$. In a total of 221 medication errors, $127(57.46 \%)$ were actual errors (medication error) and $94(42.53 \%)$ were categorized as potential errors (No error). The details of gender-wise distribution of patients in our study showed high incidence of medication errors in male 122 (61.30\%) over Females 77 $(38.70 \%)$ Table 1 . In the study maximum prescriptions were from the patients of the age group of 15-85years $(77.89 \%)$ followed by paediatrics $0-14$ years $(22.11 \%)$ as shown in Table 2.

Williams et al. ${ }^{9}$ reported the rate of medication errors in the US varies between 2 and 14\% of patients admitted to hospitals, with $1-2 \%$ of total number of patients were harmed due to medication errors. But our study shows higher incidence of medication errors 199 (29.22\%). This shows underdevelopment of clinical pharmacy services in India.

In the study, a total of 221 medication errors were observed, among them prescribing errors 183 (82.80\%), administration errors $23(10.40 \%)$, dispensing errors 08 (3.61\%) and monitoring errors $07(3.16 \%)$ as shown in Table 3. Prescribing errors $(82.80 \%)$ is the most common among the other type's errors in our study which is similar to the study conducted by Lustig A and Gabriella R. ${ }^{10}$

On evaluation of prescribing errors from the collected data,

\begin{tabular}{|c|c|c|}
\hline Age Group & Total No. of Errors & Total \% \\
\hline $\begin{array}{c}\text { Adults } \\
(15-60) \\
\text { and Geriatrics } \\
\text { (more than 60) }\end{array}$ & 155 & $77.89 \%$ \\
\hline $\begin{array}{c}\text { Paediatrics } \\
(01-14)\end{array}$ & 44 & $22.11 \%$ \\
\hline
\end{tabular}

\begin{tabular}{ccc}
\hline Table 3: Types of Medication Errors. & \\
\hline Type & $\begin{array}{c}\text { No. of Medication } \\
\text { errors }\end{array}$ & $\%$ of errors \\
\hline Prescribing errors & 183 & $82.80 \%$ \\
Administration errors & 23 & $10.40 \%$ \\
Dispensing errors & 08 & $3.61 \%$ \\
Monitoring errors & 07 & $3.16 \%$ \\
\hline
\end{tabular}

it was found that dose / strength error were encountered in 78 prescriptions $(42.62 \%)$, followed by duplication error $39(21.31 \%)$, frequency error 19 (10.38\%), generic / brand name error 08 (4.37\%), unnecessary drug 07 $(3.82 \%)$, timing error $07(3.82 \%)$, duration error 06 $(3.27 \%)$, interaction error 05 (2.73\%), omission error 05 $(2.73 \%)$, contraindication error $04(2.18 \%)$, wrong route $04(2.18 \%)$, incorrect drug 01 (0.54\%), as shown in Table 4. The large number of Dose/Strength error encountered in our study $42.62 \%$ is comparable to the study conducted by Fatemeh $\mathrm{D}$ et al. ${ }^{11}$ in which the Dose/Strength error is the most common type of prescribing error $(11.8 \%)$.

Among the errors related to administration i.e 23 $(10.74 \%)$, maximum errors were nurse centered 17 (73.91\%) as shown in Table 5 which is comparable to the study conducted by Fatemeh $\mathrm{D}$ et al. ${ }^{11}$ in which the Adminstration errors were reported to be $63.06 \%$. They found that the highest portion of errors were related to the nurses and that of patient centered were $6(26.08 \%)$.

In administration errors, underlying causes for medication error was wrong time error 10 (43.47\%) followed by omission errors $05(21.73 \%)$ and wrong duration 03 $(13.04 \%)$. The drug was not prescribed but given/taken in $03(13.04 \%)$ instances, followed by wrong frequency and wrong route in 01 (4.34\%) cases. And other parameters like wrong strength, wrong drug, improper dose/ quantity and wrong dosage form were not found $00(0 \%)$ as shown in Table 6. The study conducted by Kenneth NB et al. ${ }^{12}$ shows similar results in which the most frequent errors by category were wrong time errors $(43 \%)$ and omission errors $(30 \%)$. And the type of dosage form involved in medication administration errors are injections 14 $(60.86 \%)$ and tablets $09(39.13 \%)$ as shown in Table 7.

\begin{tabular}{ccc}
\hline Table 4: Medication Error due to Prescribing. \\
\hline Parameters & $\begin{array}{c}\text { No. of } \\
\text { Errors }\end{array}$ & \% of Errors \\
\hline Dose / Strength Error & 78 & $42.62 \%$ \\
Duplication Error & 39 & $21.31 \%$ \\
Frequency Error & 19 & $10.38 \%$ \\
Generic / Brand Name Error & 08 & $4.37 \%$ \\
Unnecessary Drug & 07 & $3.82 \%$ \\
Timing Error & 07 & $3.82 \%$ \\
Duration Error & 06 & $3.27 \%$ \\
Interaction Error & 05 & $2.73 \%$ \\
Omission Error & 05 & $2.73 \%$ \\
Contraindication Error & 04 & $2.18 \%$ \\
Wrong Route & 04 & $2.18 \%$ \\
Incorrect Drug & 01 & $0.54 \%$ \\
\hline
\end{tabular}

Indian Journal of Pharmacy Practice, Vol 11, Issue 4, Oct-Dec, 2018 
Among the errors related to dispensing, maximum errors are related to wrong $\mathrm{drug} /$ form selected 06 (75\%), followed by wrong quality error were $02(25 \%)$ as shown in Table 8.

Among the errors related to monitoring, the only instance in which the error was reported was that the Monitoring requested but not done $07(100 \%)$ as shown in Table 9.

In this study, we found that medication error was more with the Anti-microbial class of drugs 45 (21.02\%), followed by Diuretics 28(13.08\%), Drugs acting on CVS 26 (12.14\%), Non-Steroidal anti-inflammatory drugs 23 (10.74\%), Gastro-intestinal agents 21 (9.81\%), Drugs acting on CNS 19 (8.87\%), Vitamins 19 (8.87\%),Drugs acting on Liver 6 (2.80\%), Beta- Histamines 5 (2.33\%), Drugs acting on Respiratory system 4 (1.86\%), Corticosteroids $4(1.86 \%)$, Platelets and anti-platelet drugs $3(1.40 \%)$, Anti-coagulants $3(1.40 \%)$, followed by Electrolytes, Diabetic drugs, Drugs acting on Pancreas and Anti histamine drugs were found to be $2(0.93 \%)$ as shown in Table 10.

Table 5: Administration Errors (Who made Administration Error).

\begin{tabular}{ccc} 
Type & No. of Errors & \% of Errors \\
\hline Nurse Centered & 17 & $73.91 \%$ \\
Patient Centered & 06 & $26.08 \%$ \\
\hline
\end{tabular}

\section{Table 6: Administration Errors (Type of Errors).}

\begin{tabular}{ccc}
\hline Parameters & No. of Errors & $\%$ of Errors \\
\hline Wrong Time & 10 & $43.47 \%$ \\
Omission Errors & 05 & $21.73 \%$ \\
Drugs Not Prescribed But Given & 03 & $13.04 \%$ \\
Wrong Duration & 03 & $13.04 \%$ \\
Wrong Frequency & 01 & $4.34 \%$ \\
Wrong Route & 01 & $4.34 \%$ \\
Wrong Drug & 00 & 00 \\
Improper Dose / Quantity & 00 & 00 \\
Wrong Dosage Form & 00 & 00 \\
Wrong Strength & 00 & 00 \\
\hline
\end{tabular}

Table 7: Type of Dosage Form involved in Administration Errors.

\begin{tabular}{ccc}
\hline Dosage Form & No. of Errors & \% of Errors \\
\hline Injection & 14 & $60.86 \%$ \\
Tablets & 09 & $39.13 \%$ \\
Syrups & 0 & $0 \%$ \\
Capsules & 0 & $0 \%$ \\
Topical & 0 & $0 \%$ \\
Others & 0 & $0 \%$ \\
\hline
\end{tabular}

Study conducted by Ahuva L et al. ${ }^{10}$ also found Antimicrobial drugs were most common class of drugs involved in medication errors (38.07\%). Study suggests that anti-microbial class of drugs need special focus.

\section{Consequences of medication errors}

Severity level assessment analysis of medication errors was done according to NCCMERP Index for

\begin{tabular}{ccc}
\hline \multicolumn{3}{c}{ Table 8: Medication Error due to Dispensing. } \\
\hline Parameters & No. & $\%$ \\
\hline Wrong Drug/ Form Selected & 06 & $75 \%$ \\
Wrong Quality Error & 02 & $25 \%$ \\
Wrong Strength Selected & 00 & 00 \\
Wrong Quantity Counted & 00 & 00 \\
Dispensing An Expired Medication & 00 & 00 \\
\hline
\end{tabular}

\begin{tabular}{ccc}
\hline Table 9: Monitoring Errors. & & \\
\hline Parameters & No. of Errors & $\%$ of Errors \\
\hline Requested But Not Done & 07 & $100 \%$ \\
Monitoring Not Requested & 00 & $00 \%$ \\
Results Not Available & 00 & $00 \%$ \\
Results Not Acted Upon & 00 & $00 \%$ \\
Others & 00 & $00 \%$ \\
\hline
\end{tabular}

\section{Table 10: Class of Drugs involved in Medication Error.}

\begin{tabular}{ccc} 
Class of Drugs & $\begin{array}{c}\text { Number of } \\
\text { Drugs }\end{array}$ & Percentage \\
\hline Anti-microbial agents & 45 & $21.02 \%$ \\
Diuretics & 28 & $13.08 \%$ \\
Drugs acting on cardiovascular & 26 & $12.14 \%$ \\
system & & \\
Non-steroidal anti-inflammatory & 23 & $10.74 \%$ \\
drugs & & \\
Gastrointestinal agents & 21 & $9.81 \%$ \\
Drugs acting on central & 19 & $8.87 \%$ \\
nervous system (CNS) & & \\
$\quad$ Vitamins & 19 & $8.87 \%$ \\
Drugs acting on Liver & 06 & $2.80 \%$ \\
Beta-Histamines & 05 & $2.33 \%$ \\
Drugs acting on respiratory & 04 & $1.86 \%$ \\
$\quad$ system & & \\
Corticosteroids & 04 & $1.86 \%$ \\
$\quad$ Platelets & 03 & $1.40 \%$ \\
Anti-coagulants & 03 & $1.40 \%$ \\
Electrolytes & 02 & $0.93 \%$ \\
Diabetic drugs & 02 & $0.93 \%$ \\
Drugs acting on Pancreas & 02 & $0.93 \%$ \\
Anti-histamines & 02 & $0.93 \%$ \\
\hline$\quad$ & & \\
\hline & &
\end{tabular}




\begin{tabular}{|c|c|c|c|}
\hline $\begin{array}{l}\text { Levels of } \\
\text { severity }\end{array}$ & $\begin{array}{c}\text { Category- } \\
\text { Type }\end{array}$ & $\begin{array}{c}\text { No of } \\
\text { medication } \\
\text { errors }\end{array}$ & $\begin{array}{c}\text { Percentage } \\
\text { of medication } \\
\text { errors }\end{array}$ \\
\hline No Error & Category- A & 94 & $42.53 \%$ \\
\hline \multirow{3}{*}{$\begin{array}{c}\text { Error No } \\
\text { Harm }\end{array}$} & Category-B & 18 & $8.14 \%$ \\
\hline & Category-C & 29 & $13.12 \%$ \\
\hline & Category-D & 51 & $23.07 \%$ \\
\hline \multirow[t]{4}{*}{ Error Harm } & Category-E & 13 & $5.88 \%$ \\
\hline & Category-F & 06 & $2.71 \%$ \\
\hline & Category-G & 01 & $0.45 \%$ \\
\hline & Category-H & 09 & $4.07 \%$ \\
\hline Error Death & Category-I & 00 & $00 \%$ \\
\hline
\end{tabular}

Table 12: Medication Errors causes and Preventive measures taken to prevent the future recurrence.

\begin{tabular}{|c|c|c|}
\hline $\begin{array}{c}\text { Type of } \\
\text { Medication Error }\end{array}$ & Causes & $\begin{array}{l}\text { Preventive } \\
\text { Measures }\end{array}$ \\
\hline $\begin{array}{l}\text { Prescription } \\
\text { Errors }\end{array}$ & $\begin{array}{l}\text { 1) Incomplete } \\
\text { prescription. } \\
\text { 2) Prescription } \\
\text { written by PG's. }\end{array}$ & $\begin{array}{l}\text { 1) Updating the } \\
\text { Drug Information. } \\
\text { 2) Using Electronic } \\
\text { Prescription Record } \\
\text { (EPR) can prevent } \\
\text { Errors. }\end{array}$ \\
\hline $\begin{array}{c}\text { Transcription } \\
\text { Errors }\end{array}$ & $\begin{array}{l}\text { 1) Lack of } \\
\text { communication. } \\
\text { 2) Increase in } \\
\text { workload } \\
\text { 3) Staffing alternative } \\
\text { hours. }\end{array}$ & $\begin{array}{l}\text { 1) Medication chart } \\
\text { should be followed } \\
\text { regularly by nurses. }\end{array}$ \\
\hline $\begin{array}{l}\text { Administration } \\
\text { Errors }\end{array}$ & $\begin{array}{l}\text { 1) Lack of } \\
\text { Knowledge. } \\
\text { 2) Staffing } \\
\text { Insufficient. } \\
\text { 3) Increase in } \\
\text { workload. }\end{array}$ & $\begin{array}{l}\text { 1) Educating the } \\
\text { Nurses. } \\
\text { 2) Aduequate } \\
\text { staffing. }\end{array}$ \\
\hline Dispensing Errors & $\begin{array}{l}\text { 1) Peak Hour. } \\
\text { 2) Improper stock } \\
\text { arrangements } \\
\text { 3) Storage problem. } \\
\text { 4) Staffing } \\
\text { Insufficient. }\end{array}$ & $\begin{array}{l}\text { 1) Aduequate } \\
\text { staffing. } \\
\text { 2) Proper stock } \\
\text { arrangements and } \\
\text { drugs storage. }\end{array}$ \\
\hline Monitoring Errors & $\begin{array}{l}\text { 1) Failure to adhere } \\
\text { to work procedure. } \\
\text { 2) Multitasking. }\end{array}$ & $\begin{array}{l}\text { 1) Adherance to } \\
\text { work procedure. }\end{array}$ \\
\hline Omission error & $\begin{array}{l}\text { 1) Failure to adhere } \\
\text { to work procedure. } \\
\text { 2) Drugs written in } \\
\text { multiple charts. }\end{array}$ & $\begin{array}{l}\text { 1) Adherance to } \\
\text { work procedure. } \\
\text { 2) Drugs written in } \\
\text { single chart. }\end{array}$ \\
\hline
\end{tabular}

Categorizing Medication Errors. Most of the errors in our study resulted in No Error $42.53 \%$ (category A), $44.34 \%$ (category B, C and D) resulted in Error No Harm, 13.12\% (category E, F, G, H) resulted in Error Harm. No incidence of Error Death was reported due to medication errors as shown in Table 11.
Table 13: Examples of potential medication error.

\begin{tabular}{cc} 
Name of drugs & Medication errors \\
\hline Ranitidine & Tab. Ranitidine was prescribed as \\
$40 \mathrm{mg}$, which after consultation with \\
prescriber it was modified as Tab. \\
Ranitidine $150 \mathrm{mg}$.
\end{tabular}

Furosemide

Inj. Furosemide was prescribed as 60 $\mathrm{mg}$, which is not an available dose. After consultation with the physician the dose was corrected.

Esomeprazole

Tab. Esomeprazole was written as 40 gms, which is available in $40 \mathrm{mg}$. After consultation with the physician it was corrected as $40 \mathrm{mg}$.

Vit $-\mathrm{K}$

Vit - $\mathrm{K}$ was prescribed to give in IV route, which should be given through IM route. After consultation with the physician the route was changed to IM.

Lasilactone

(Furosemide+ Spiranolactone)

Lasilactone was prescribed in tablet form, but it is available in capsule form. After consultation with the physician it was corrected.

Buscopan

Tab. Buscopan was prescribed as $4 \mathrm{mg}$, which is not an available dose. After the consultation with the physician the dose was corrected to $10 \mathrm{mg}$.

Meclizine Tab. Meclizine was prescribed as 10 $\mathrm{mg}$, but it is available in $8 \mathrm{mg}, 16 \mathrm{mg}$ and $32 \mathrm{mg}$. After the consultation with the physician the dose was corrected to $8 \mathrm{mg}$.

Atorvastatin Tab. Atorvastatin was prescribed at morning. Statins are normally prescribed during nights. After the consultation with the physician, the drug was given at night.

Tazobactam Inj. Advent was prescribed without mentioning the dose. It is available in $4.5 \mathrm{gm}, 2.25 \mathrm{gm}, 1.2 \mathrm{gm}$. After the consultation with the physician the dose was mentioned as $4.5 \mathrm{gm}$.

The results found in our study were comparable to the study conducted by Sanjay $G$ et al. ${ }^{8}$ in which morbidity was not significant in Most of the errors(66.49\%).,16.23\% resulted in mild morbidity, $10.49 \%$ patients suffered from moderate morbidity, while $6.28 \%$ of the patients experienced severe morbidity. And our study is also comparable to the study conducted by Mansi $\mathrm{P}$ et al. ${ }^{13}$ where morbidity was nil in $82 \%$, mild in $10.7 \%$, moderate in $4.8 \%$ and severe in $2.4 \%$ errors.

Medication Errors causes and Preventive measures taken to prevent the future recurrence are described in Table 12. Some of the Potential medication error occurred in our study are shown in Table 13.

Indian Journal of Pharmacy Practice, Vol 11, Issue 4, Oct-Dec, 2018 


\section{CONCLUSION}

Medication error in the health care system is the most common phenomenon. Study results shows that overall incidence of medication errors was found to be high even though there were no life threatening events. In our study prescribing errors were the most common type of medication error. Study concludes that there was higher incidence of medication errors related to antibiotics. Study results shows that there was more number of potential errors. clinical pharmacist can play an important role in prevention of these errors by working with the health care professionals which is highly appreciable.Categorization of errors in our study was done according to NCCMERP Index for assessing the severity of Medication Errors. Most of the errors in the study resulted in No Harm. No death was reported due to medication errors. Development of medication error reporting and management system at hospital can prevent further occurrence of medication errors. Clinical pharmacist plays an vital role in Identification and prevention of medication errors and pharmacist should work with health care team for the betterment of quality of life of the patients.

\section{ACKNOWLEDGEMENT}

The authors are sincerely thankful to HOD, Department of Medicine and Paediatric for supporting the work.

\section{CONFLICT OF INTEREST}

The authors declare no conflict of interest.

\section{ABBREVIATIONS}

ME: Medication Errors; NCCMERP: National Coordinating Council for Medication Error Reporting and Prevention; WHO: World Health Organisation; ADE: Adverse Drug Event; ASHP: The American Society of Health system Pharmacists; AZT: Zidovudine; CPOE: Computerised Physician Order Entry; CPR: Cardio Pulmonary Resuscitation; DUR: Drug Utilisation Reviews; ENT: Ears, Nose and Throat; EPR: Electronic Prescription Error; FDA: Food and Drug Administration; $\mathrm{FeSO}_{4}$ : Ferrous Sulfate; HKES: Hyderabad Karnataka Educational Societies; ICU: Intensive Care Unit; IPD: In Patient Department; ISMN: Iso Sorbide Mono Nitate; ISMP: Institute for Safe Medication Practices; IV: Intra Venous; JC: Joint Commission.

\section{SUMMARY}

Medication errors are a preventable event that may cause or lead to inappropriate medication use or patient harm while the medication is in the control of the healthcare professional and patient. Pharmacists possess valuable expertise and training. With their background in assessing and resolving medication use system deficiencies, they are in a unique position of being appropriate initiators of a collaborative interdisciplinary dialogue.

Strength of the study: The present study reviews the present prescribing trends at the study site. The study can be utilized as a tool by the researchers in order to carry out the same at larger scale.

Limitations of the study: The study was conducted on a small sample size and Patients enrolled Randomly therefore larger sample size would give a better outcome.

Controversies: No controversies were raised during the study

\section{REFERENCES}

1. Gabriella RD, Eloni TR, José RG. Medication errors: classification of seriousness, type and of medications involved in the reports from a University Teaching Hospital. Brazilian Journal of Pharmaceutical Sciences.2013;49(4):793-802.

2. Kadir A, Subish P, Anil K, Ram B. Pattern of potential medication errors in a teritiary care hospital in Nepal. Ind J of Pract. 2010;3(2):16-22.

3. Kohn L, Corrigan J, Donaldson M. To Err is Human: Building a Safer Health System. Washington DC: Institute of Medicine; 1999;1-8.

4. Shargel, Mutnick, Souney, Swanson. A Text Book on Comprehensive pharmacy Review. 2010;7:499-506.

5. Makeham MAB, Dovey SM, County M, Kidd MR. An international taxonomy for errors in general practice: a pilot study. MJA. 2002;177(2):68-72.

6. Reddy LK, Modi AG, Chaudhary B, Modi V, Patel M. Medication Errors - A Case Study. Journal of the Academy of Hospital Administration. 2009;21(1-2):28-34.

7. Parthasarthi G. A Text Book Oo Clinical Pharmacy Practice. 2004:1(1):1425-6.

8. Sanjay G, Ajaykumar S, Bhavana S. Medication errors in medicine wards in a tertiary care teaching hospital of a hill state in India. Asian Journal of Pharmacy and Life Science. 2012;2(1):56-63.

9. Williams DJP. Medication errors. J Royal College of Physicians of Edinburgh. 2007;37:343-6.

10. Ahuva L. Medication error prevention by pharmacists - An Israeli solution. Pharm World Sci. 2000;22(1):21-5.

11. Fatemeh D, Arash $R$, Hassan $T$, Sara A, Somayaeh $H$, Shadi F, et al. Medication Errors in a Emergency Department in a Large Teaching Hospital in Tehran, Iran. Iranian Journal of Pharmaceutical Research. 2013;12(4):937-42.

12. Kenneth NB, Elizabeth AF, Ginette AP, David WB, Robert EM. Medication Errors Observed In 36 Health Care Facilities in Georgia and Colarado. Arch Intern Med. 2002;162(16):1897-903.

13. Mansi P, Passi GR. Medical errors in pediatric practice. Indian Pediatrics. 2008;45(7):586-9. 